\title{
Optimization of Saponification Process for Orange and Apple Wastes
}

\author{
K. N. Ghimire ${ }^{1 *}$ and K. Inoue ${ }^{2}$ \\ 1. Central Department of Chemistry, Tribhuvan University Kirtipur, Kathmandu, Nepal \\ 2. Department of Applied Chemistry, Saga University, Saga 840-8502, Japan
}

\begin{abstract}
A cheap, efficient and environmentally friendly bio-adsorbent is prepared from orange and apple juice residue by saponification process. The measure of adsorption capacity of such adsorbent is its total amount of exchangeable protons which differs drastically depending on the conditions of saponification. The most optimum condition of saponification process rendered exchangeable protons of about $2.6 \mathrm{~mol} / \mathrm{kg}$. The adsorption of heavy metal ions like lead, iron and copper has examined on the prepared bio-adsorbent at different $\mathrm{pH}$ values.
\end{abstract}

\section{Introduction}

Metal ion pollution in water is one of the burning problems in different parts of the world. People are using several kinds of synthetic as well as naturally available adsorbent for the removal of such metal ions. But such adsorbent are either very expensive or not much effective in removing such metal ions. For the commercial application, the adsorbent used for the removal of harmful metal ions from water should be cheap. So in recent years, much attention has been given to removal of metal ions like arsenic, lead, iron, etc by using bio-adsorbent due to its excellent adsorption behavior for metal ions, low cost purification and its environmentally friendly nature compared to other synthetic ion-exchanging resins. ${ }^{1-5}$

The bio-adsorbent from orange and apple juice residue can be prepared by saponifying the orange and apple juice residue. The juice residue contains pectin substance [6] and during saponification the methylated ester part of pectin is converted into calcium carboxylate group as shown below:-

Then calcium carboxylate group acts as ion-exchange site. So, the saponificated orange juice residue (SOJR) and saponificated apple juice residue (SAJR) can be used as bio-adsorbent which adsorbs metal ions by ion exchange mechanism. But its effectiveness depends on the extent of ester part conversion of pectin into carboxylate part which was dependant on $\mathrm{pH}$ value during saponification and the time as well. In this context, this research work is carried out to obtain most suitable condition of 
saponification and adsorption of various metal ions like copper, iron and lead are studied on the prepared bio-adsorbent at different $\mathrm{pH}$ values.

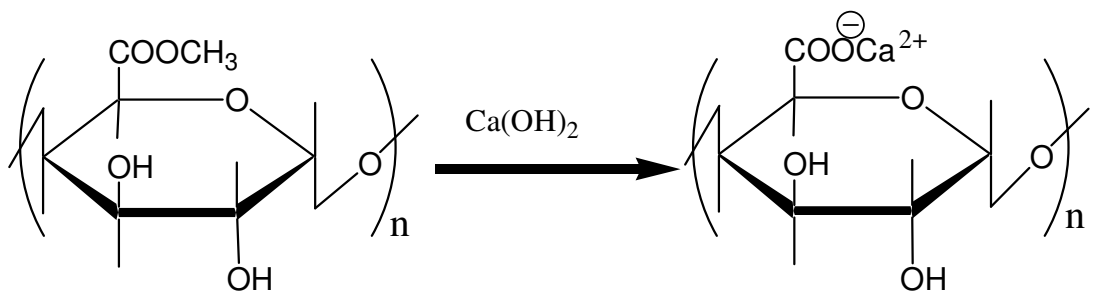

\section{Experimental Methods}

\section{Preparation of saponificated orange juice residue (SOJR)}

$100 \mathrm{gm}$ of crude wet orange waste was taken just after juicing. Such wet residue was saponificated by adding water and calcium hydroxide in appropriate amount so as to maintain the $\mathrm{pH}$ at $9,10,10.5,11,12,12.5$ and 13 . In addition to calcium hydroxide, sodium hydroxide was added to maintain $\mathrm{pH}$ greater than 11 . The suspension was shaken in vibrating shaker for 24 hours. Thus prepared SOJR was thoroughly washed with distilled water till neutral $\mathrm{pH}$. After that SOJR was filtered and dried in oven at $60^{\circ} \mathrm{C}$ for $24 \mathrm{~h}$.

\section{Preparation of $\mathrm{H}^{+}$-form SOJR gel}

$2 \mathrm{gm}$ of the prepared SOJR at different $\mathrm{pH}$ was taken in different stopper bottles and $500 \mathrm{~mL}$ of $0.1 \mathrm{M}$ hydrochloric acid was added to it. The $\mathrm{H}^{+}$-SOJR gel was shaken for 2 hours. After washing the SOJR with $\mathrm{HCl}$, the gel was washed with distilled water till neutrality followed by decantation. Then thus prepared hydrogen-form gel was filtered and dried in oven at $70^{\circ} \mathrm{C}$ for $24 \mathrm{~h}$.

\section{Determination of total exchangeable proton}

$50 \mathrm{mg}$ of each of thus prepared hydrogen-form gel were taken along with $30 \mathrm{~mL}$ of $0.01 \mathrm{M}$ sodium hydroxide solution in five separate stopper bottles and were equilibrated for $24 \mathrm{~h}$ at $25^{\circ} \mathrm{C}$. The decrease in hydrogen ion concentration was evaluated by titrating the filtrate with $0.01 \mathrm{M}$ hydrochloric acid solution using phenolphthalein as an indicator.

\section{Saponification of orange waste with respect to time}

The procedure was the same as mentioned above but the saponification was carried out as a function of time at $\mathrm{pH} 12$.

Preparation of saponificated apple juice residue (SAJR) 
The procedure was the same with that of SOJR as mentioned above and apple waste was taken instead of orange waste.

\section{Adsorption test of metal ions of $\mathrm{Cu}, \mathrm{Pb}$ and $\mathrm{Fe}$}

All of the adsorption tests for copper, lead and iron on SOJR and SAJR were carried out batch wise. $35 \mathrm{mg}$ of the dried adsorbent was taken in a conical flask together with 20 $\mathrm{mL}$ of the $1 \mathrm{mM}$ metal ion solution. The flask was shaken vigorously in a shaker at room temperature for 24 hours to attain equilibrium. The concentration of the corresponding ion at different $\mathrm{pH}$ before and after adsorption was measured using atomic absorption spectrophotometer. The $\mathrm{pH}$ of the solution was maintained by using potassium hydrogen phthalate and sodium hydroxide in appropriate amount.

From the metal ion concentrations measured before and after adsorption $\left(\mathrm{C}_{\mathrm{o}}\right.$ and $\mathrm{C}_{\mathrm{e}}$, respectively), the percentage adsorption of the metal ( $\mathrm{R} \%)$ was calculated according to equation 1.

$$
R=\frac{C_{0}-C_{e}}{C_{0}} \times 100
$$

\section{Evaluation of exchangeable protons}

From the alkali concentration measured before and after attaining equilibrium with $\mathrm{H}^{+}$- SOJR gel $\left(\mathrm{C}_{\mathrm{o}}\right.$ and $\mathrm{C}_{\mathrm{e}}$, respectively), the dry weight of the $\mathrm{H}^{+}$-SOJR gel $\left(\mathrm{W}_{\mathrm{Gel}}\right)$ and the volume of alkali taken (V), the total ion-exchanging capacity (q) was calculated by using equation 2.

$$
\mathrm{q}=\frac{C_{0}-C_{e}}{W_{G e l}} \times V
$$

$[\mathrm{mol} / \mathrm{kg}]$

\section{Results and Discussion}

Figure 1 shows the effect of $\mathrm{pH}$ for the saponification of orange juice residue. This figure shows that the total exchangeable protons increases continuously on increasing $\mathrm{pH}$ up to $\mathrm{pH} 12$ and after that it becomes almost constant. So the $\mathrm{pH}$ value 12-13 is observed to be optimal $\mathrm{pH}$ condition for saponification at which total ion-exchanging capacity (exchangeable protons) is found to be maximum. 


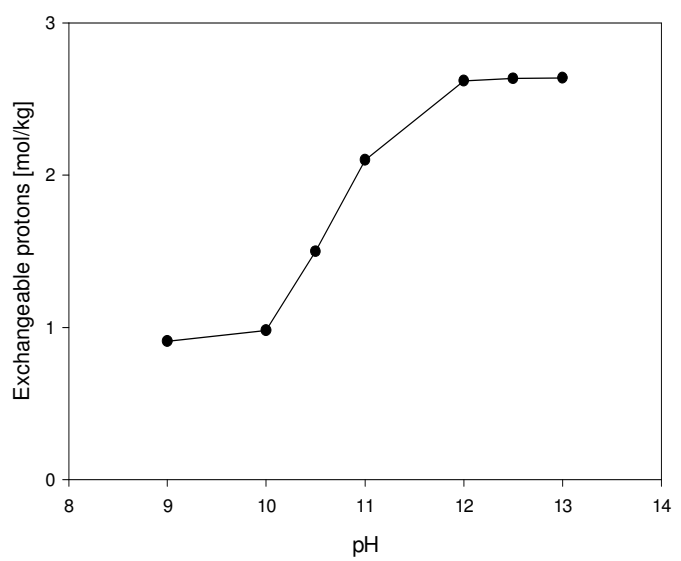

Figure 1: Effect of $p H$ for the saponification of orange juice residue. $p H \geq 11$ was maintained by sodium hydroxide.

Figure 2 shows the effect of time for saponification of orange juice residue. The figure shows that the total ion-exchanging capacity which is represented in the figure in terms of exchangeable protons is increasing with the time of saponification and reaches to a constant value after the equilibrating time reaches around $24 \mathrm{~h}$. So the observed optimal time required for saponification was 24 hours.

Figure 2: Evaluation of exchangeable protons with respect to time at $\mathrm{pH} 12.5$.

\section{Adsorption tests of metal ions of $\mathrm{Cu}, \mathrm{Pb}$ and $\mathrm{Fe}$}

Figure 3 (a) shows the amount of adsorption of $\mathrm{Cu}, \mathrm{Pb}$ and $\mathrm{Fe}$ on SOJR as the function of equilibrium $\mathrm{pH}$. Adsorption is increasing with increasing $\mathrm{pH}$ and the affinity for the lead ion is highest as compared to the other metal ions. With increasing $\mathrm{pH}$, the concentration of protons will be decreased while metal ions concentration is the same thereby letting the metal ions adsorbed through ion exchange mechanism. The same tendency for the adsorption of $\mathrm{Cu}, \mathrm{Pb}$, and $\mathrm{Fe}$ on SAJR was observed as the function of equilibrium $\mathrm{pH}$ as shown in Fig. 3 (b). 
(a)

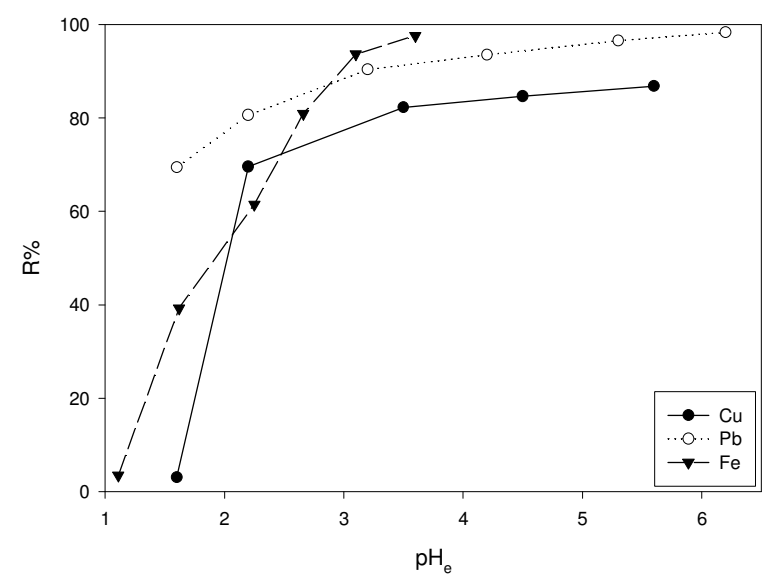

(b)

Figure 3: Removal of $\mathrm{Cu}$ (II), $\mathrm{Pb}$ (II) and Fe (II) on (a) SOJR and (b) SAJR. The $\mathrm{pH}$ of the aueous solution was maintained by using potassium hydrogen phthalate and sodium hydroxide at appropriate proportions.

\section{Conclusion}

Bio-adsorbent having high ion-exchange capacity can be easily prepared by using cheap orange and apple juice residue by simply saponifying them using very common and cheap chemicals like calcium hydroxide. The optimal condition for ester part hydrolysis of pectin component present on those fruit juice residue was observed to be $\mathrm{pH} 12-13$ and the optimal time required for saponification was found to be 22-24 hours. During saponification, the $\mathrm{pH}$ greater than 11 has to be maintained by using sodium hydroxide. Bio-adsorbent thus prepared had very high ion-exchange capacity therefore are applicable for the separation of heavy metal ions.

\section{References}

1. K. N. Ghimire, K. Inoue, T. Miyajima, K. Yoshizuka and T. Shoji, Chitin and Chitosan Research, 2001, 2, 61.

2. K. Inoue, Application of Chitosan in Separation and Purification of Metals. Recent Advances in Marine Biotechnology, Oxford \& IBH Publishing Pvt. Ltd, 1998, vol. 2, 63-97.

3. S. H. Lee, and J. W. Yang, Sep. Sci. and Technol., 1997, 32, 1371.

4. M. Tsezos, and B. Volesky, Biotechnol. Bioeng. 1981, 23, 583.

5. K. N. Ghimire, K. Inoue, K. Makino, and T. Miyajima, Sep. Sci. Technol., 2002, 37, 12, 2785.

6. S. Nagy et al., Citrus Science and Technology (Westport, Connecticut: The AVI Publishing Company, Inc.), 1977, 74, 479. 